\title{
50 ANOS DO "O DIREITO À CIDADE": REPENSANDO A (RE)PRODUÇÃO DOS CONIUNTOS HABITACIONAIS DE INTERESSE SOCIAL EM BELO HORIZONTE
}

\section{YEARS OF "THE RIGHT TO THE CITY": RETHINKING THE (RE) PRODUCTION OF HOUSING PROJECTS OF SOCIAL INTEREST IN BELO HORIZONTE}

\section{Reginaldo Magalhães de Almeida ${ }^{1}$}

\section{Resumo}

Em 2018, completam-se 50 anos da publicação da obra-manifesto denominada "O Direito à Cidade" de Henri Lefebvre, uma das mais significativas publicações da teoria urbanística do Século XX. Mais do que comemorar, os profissionais que trabalham com o espaço urbano devem refletir sobre a amplitude das ideias de Lefebvre. O objetivo deste artigo é baseado na crítica de Lefebvre presente no livro "O Direito à Cidade", analisar o processo de urbanização de parte da região noroeste de Belo Horizonte, na modalidade de grandes conjuntos habitacionais do Programa Minha Casa Minha Vida. Pretende-se demonstrar a perenidade da crítica de Lefebvre. Para o desenvolvimento deste artigo, utilizou-se como base de estudos uma pesquisa documental realizada no livro citado anteriormente e também em outras publicações de renomados críticos da questão urbana, bem como em processos administrativos de conjuntos habitacionais, destinados para a população de menor poder aquisitivo, implantados em Belo Horizonte, a partir de 2010. Conclui-se que, apesar de transcorridas décadas de publicação do livro "O Direito à Cidade", as suas ideias devem ser revividas e discutidas mais uma vez, pois intervenções patrocinadas por grupos privilegiados e sobre a tutela do Estado com o discurso modernizador e que excluem a maioria da população, dominam ainda as práticas urbanas, principalmente em Belo Horizonte. Desse modo, áreas são urbanizadas pelo Estado, grandes conjuntos habitacionais de interesse social são construídos distantes do centro da cidade, dos equipamentos e serviços urbanos, destruindo a diversidade, a urbanidade, com um discurso de melhoria da qualidade de vida, que esconde o real sentido do domínio e expansão do capital.

\footnotetext{
${ }^{1}$ Doutor em Arquitetura e Urbanismo pela Escola de Arquitetura da Universidade Federal de Minas Gerais (2014), Mestrado em Arquitetura (1999 ) e Graduação em Arquitetura e Urbanismo pela EA/UFMG (1991) . Pesquisador na área da (re) produção do espaço urbano contemporâneo, Habitat Intraurbano e teorias do urbanismo. Foi professor de Projeto de Urbanismo, Planejamento Urbano, Bases Legais e Gestão Pública do curso de Arquitetura e Urbanismo do Uni-BH. E-mail: ralmeida@fumec.br
} 
Palavras chave: "O Direito à Cidade". Conjuntos Habitacionais de Interesse Social. Belo Horizonte.

\section{Abstract}

In 2018, 50 years after the publication of the manifesto entitled "The Right to the City" by Henri Lefebvre, one of the most significant publications of 20th century urban theory. More than celebrating, professionals working with urban space must reflect on the breadth of Lefebvre's ideas. The purpose of this article is based on Lefebvre's criticism in the book "The Right to the City", to analyze the urbanization process of part of the northwestern region of Belo Horizonte, in the form of large housing projects of the Minha Casa Minha Vida Program. It is intended to demonstrate the perenniality of Lefebvre's critique. For the development of this article, a documentary research was carried out in the book mentioned above and also in other publications of renowned critics of the urban question, as well as in administrative processes of housing complexes, destined for the population of lower purchasing power, implemented in Belo Horizonte, from 2010. It can be concluded that, despite decades of publication of the book "The Right to the City", its ideas must be revived and rediscussed, since interventions sponsored by privileged groups and on guardianship of the State with the modernizing discourse and that exclude the majority of the population, still dominate the urban practices, mainly in Belo Horizonte. In this way, areas are urbanized by the state, large social housing units are built far from the city center, urban equipment and services, destroying diversity, urbanity, with a discourse to improve the quality of life that conceals the real meaning of domination and expansion of capital.

Keywords: "The Right to the City". Households of Social Interest. Belo Horizonte. 


\section{INTRODUÇÃO}

As cidades sobre a influência da industrialização, principalmente a partir do Século XIX, ampliaram a sua atratividade, como um local destinado a absorver o avanço tecnológico da humanidade, ao mesmo tempo em que, no seu espaço, conformaram uma série de conflitos e problemas urbanos, como a poluição, o déficit habitacional e o de infraestrutura, os congestionamentos nos sistemas de transportes e, fundamentalmente, as enormes desigualdades socioespaciais. Estas foram estimuladas, dentre outras causas, pelo Estado e por estratégias de grupos sociais, como a burguesia. Os problemas citados anteriormente, que acompanhavam o processo de produção e reprodução urbana, ainda hoje, são comuns às grandes cidades no mundo capitalista e, particularmente, nos países da América Latina.

Diante desse panorama urbano, em meados do Século XIX, consolidaram-se as práticas de intervenções na cidade, desenvolvidas pela ciência do Urbanismo Moderno. A burguesia, detentora da propriedade imobiliária estabelece um acordo com o Estado, que passa a intervir, a criar regulamentos e a executar obras necessárias aos interesses dos primeiros. O valor de troca se impõe sobre o valor de uso, antes dominante nas cidades, destrói e reconstrói bairros antigos de acordo com seus interesses, quebra laços familiares, impõe projetos urbanos, desloca moradores do centro da cidade, dentre outas práticas, sem a participação da maioria da população, principalmente a de menor poder aquisitivo.

Essas práticas do Urbanismo Moderno passam a receber dos estudiosos da cidade uma grande crítica. Dentre esses teóricos, destaca-se o filósofo francês Henri Lefebvre (1901-2006). Ele repudia a postura determinista e metafísica do Urbanismo Moderno. Defende que os problemas da sociedade não podem ser todos reduzidos a questões espaciais, muito menos à prancheta de um arquiteto. Avesso ao planejamento como uma estratégia de classe, que pretende resolver em definitivo os problemas sociais ao custo do domínio do valor de troca e da perda da urbanidade, Lefebvre, em 1968, concebe sua obra-manifesto, denominada "O Direito à Cidade". No final do Século XX, as ideias presentes no seu livro subsidiaram muitos estudos nas áreas do planejamento urbano, tornando também referência de muitos movimentos sociais.

O ano de 2018 marca os 50 anos da publicação do livro "O Direito à Cidade". Assim sendo, considerando a importância da comemoração do lançamento de uma publicação 
referência dos estudos da cidade, esse artigo tem o objetivo de explorar criticamente a perenidade das ideias revolucionárias do autor sobre as práticas urbanas. Para tanto, pretendese analisar, baseado na crítica do "O Direito à Cidade", o processo contemporâneo de urbanização de parte da região noroeste de Belo Horizonte, baseado na implantação de grandes conjuntos habitacionais de interesse social do Programa Minha Casa Minha Vida (PMCMV), destinados à população de menor poder aquisitivo.

Para desenvolvimento deste artigo, uma ampla pesquisa documental foi realizada, em arquivos da Prefeitura de Belo Horizonte (PBH), onde estão disponíveis dados sobre os conjuntos licenciados e/ou em processo de licenciamento na região noroeste de Belo Horizonte. Utilizou-se como base da estrutura teórica, a crítica de Lefebvre e livros referenciais da historiografia urbanística.

A história de ocupação dessa região, considerada também como Regional Noroeste, está ligada às origens da capital de Belo Horizonte. Corresponde a uma grande porção territorial, que se estende desde o centro da cidade até a divisa com outros municípios da Região Metropolitana de Belo Horizonte (RMBH). Hoje, a região é caracterizada por grandes diferenças sociais e econômicas. Além disso, possui significativa relevância ambiental por concentrar as últimas grandes áreas livres da cidade e centralizar, segundo dados da Prefeitura de Belo Horizonte (PBH), desde 2000, a maior parte dos programas públicos e privados de habitação de interesse social da capital.

Decorridos 50 anos lançamento do livro "O Direito à Cidade", torna-se oportuno um reestudo das observações de Lefebvre sobre as cidades, para ampliar o entendimento sobre o mundo e retirar lições para o presente e futuro das práticas urbanas contemporâneas. Entendese, que o autor merece destaque pelo seu manifesto, ainda atual, de desafiar as políticas de intervenção no espaço urbano.

\section{DA CRÍTICA AO URBANISMO MODERNO AO DIREITO À CIDADE}

O projeto intelectual de Lefebvre liga-se ao pensamento de Karl Marx (1818-1883). Segundo Martins (1996, p. 13), Lefebvre "[...] busca prolongar o pensamento de Marx e desenvolvê-lo em função do que há de novo depois de um século no mundo moderno". Entre os anos 1930 e 1950, Lefebvre, como membro do Partido Comunista Francês (PCF), desenvolveu uma atuação cercada de controvérsias, culminando com sua expulsão do PCF, em 1958, e a rejeição de seus livros e ideias pelos comunistas. Ao longo de sua trajetória de vida, 
produziu aproximadamente setenta livros, publicou uma centena de artigos, traduziu as obras de Karl Marx, Friedrich Engels (1820-1895), Vladimir Lenin (1870-1924) e desenvolveu, por um grande período, estudos com o teórico Guy Debord (1931-1994) e os situacionistas franceses² (MERRIFIELD, 2006).

Lefebvre também elaborou uma vasta pesquisa histórica e sociológica na região dos Pirineus, França, resultando, nos anos de 1940, em sua tese de doutorado em Sociologia Rural (DEULCEUX; HESS, 2009). Ele publicou, no início dos anos de 1960, severas críticas acerca da experiência de Mourenx, cidade construída segundo os princípios do Urbanismo Moderno, em 1958, a poucos quilômetros de sua cidade natal, nos Pirineus. Mourenx representava para ele a negação de características que julgava importantes para a cidade, tais como, o encontro, a diversidade e o imprevisível (MERRIFIELD, 2006).

A aproximação com o rural e os novos projetos de cidade refletiram, dentre outros, no pensamento de Lefebvre sobre as repercussões do avanço e domínio da industrialização e o capitalismo sobre o cotidiano das pessoas e os espaços rural e urbano. Tal pensamento norteou publicações do autor, a partir da década de 1960, que se tornaram referências para se compreender as contradições da sociedade contemporânea.

Nas publicações entre o final da década de 1960 e meados de 1970, Lefebvre expôs com mais vigor as contradições do espaço urbano resultantes do processo de expansão do capitalismo. Em 1968, publica o livro "O Direito à Cidade", referência dos estudos contemporâneos sobre o espaço urbano, que é entendido como um direito inalienável à vida, possível por meio da construção da cidade mais voltada ao novo humanismo, mais próxima dos encontros, dos desencontros, dos desejos que se manifestam no espaço da urbanidade (LEFEBVRE, 2006).

O propósito de seu livro não é apenas estudar e criticar as ideologias e práticas urbanas, mas também trazer as questões urbanas para o campo político. Nele, é nítida a crítica acerca das forças que produzem a segregação nas cidades, por meio do próprio sistema que impõe

\footnotetext{
${ }^{2}$ Situacionismo consiste em um movimento europeu de crítica social, cultural e política, que teve início na década de 1950, e reuniu poetas, arquitetos, cineastas, artistas plásticos e outros profissionais. 0 grupo definiu-se como uma "vanguarda artística e política", apoiada em teorias críticas à sociedade de consumo e à cultura mercantilizada. Do ponto de vista artístico, as principais fontes do movimento foram o dadaísmo e o surrealismo, movimentos que contestavam o racionalismo artístico. Os livros "História e Consciência de Classe", de Georg Lukács (1885-1971), a edição dos dois primeiros volumes da "Crítica da Vida Cotidiana", de Lefebvre, "A sociedade do espetáculo" de Guy Debord, junto com as reflexões dos pensadores da Escola de Frankfurt, entre outros, marcam a reflexão social, cultural e política situacionista, que apontam para os efeitos perversos do capitalismo e a necessidade de alterar a ordem social pela reinvenção da vida cotidiana (MONTANER, 2012).
} 
sobre a sociedade. O autor desvela que o domínio do valor de troca e a consequente disseminação da mercadoria pela industrialização vêm destruindo a cidade, bem como a realidade urbana, subordinando o uso aos imperativos da lógica capitalista. Exemplifica que essas forças contribuíram para a expansão do que denominou como "tecido urbano", ou seja, o conjunto das manifestações relativo ao predomínio da cidade sobre o campo, tema explorado por outros autores, como Monte-Mór (2006). Para Lefebvre (2006, p. 23):

Ao mesmo tempo, neste tecido e mesmo em outros lugares, as concentrações urbanas tornam-se gigantescas; as populações acumulamse atingindo densidades perturbadoras (por unidade de área ou habitação). As pessoas se deslocam para periferias distantes, residenciais ou produtivas. Os escritórios substituem a habitação em centros urbanos.

Ao se referir à sua publicação, Lefebvre $(2006$, p. 2) afirma que ela "[...] não se propõe apenas passar pelo crivo da crítica os pensamentos e as atividades que dizem respeito ao urbanismo. Tem por objetivo fazer com que estes problemas entrem na consciência e nos programas políticos." O argumento norteador do autor é que "a industrialização caracteriza a sociedade moderna" (LEFEBVRE, 2006, p. 3). Hoje, a rapidez de informações e o avanço de novas tecnologias caracterizam a sociedade contemporânea, embora, em países como o Brasil, a industrialização ainda influência no processo de (re)produção do espaço urbano (BAUMGARTEN, 2012).

O ponto de partida da análise de Lefebvre é a crítica da conjunção do processo de industrialização e da urbanização. Nas cidades, aponta que existe toda uma luta entre os bens móveis (capital) e imóveis (palácios, monumentos), valor de uso versus o domínio do valor de troca, que favorecem a acumulação de capital e os interesses de determinados grupos, os quais promovem consequências transformadoras das cidades e da sociedade urbana. Segundo o autor:

[...] a cidade e a realidade urbana dependem do valor de uso. O valor de troca e a generalização da mercadoria pela industrialização tendem, ao subordiná-las a si, a destruir a cidade e a realidade urbana [...] (Lefebvre, (2006, p. 14)

Para Lefebvre, a industrialização promotora do processo de urbanização levou à perda do direito à vida urbana, do direito à cidade, através da planificação do espaço que tende à expansão e implosão, da estratégia de classe, das ações do Estado, empresas privadas e meios de comunicação de massa.

A resposta aplicada pela burguesia foi espacial: o proletariado foi gradualmente expulso do centro da cidade, além dos antigos subúrbios, aos poucos integrados em Paris, diretamente com o urbanismo Haussmann ou indiretamente através da especulação imobiliária. Harvey 
(2012), consentindo com Lefebvre, afirma que a missão de Haussmann foi a de resolver o problema do excedente resultado da industrialização através da urbanização de Paris, que absorveu trabalho e o capital, gerando estabilidade social e atendendo aos interesses políticos da classe burguesa.

Um dos acontecimentos políticos mais significativos, que antecedem o surgimento dessas práticas adotadas pelo Urbanismo Moderno, foi a revolução francesa de 1848, que representou, como assinala Benevolo (2010, p. 182), "um momento de revisão ideológica”. Em vários países da Europa, explodiram verdadeiras revoluções dirigidas pela burguesia que se aliou aos trabalhadores para derrubar reis e imperadores. A nova classe detentora do capital era a burguesia industrial, que queria ter o poder político em suas mãos.

Como consequência desses acontecimentos, legislações são promulgadas com o objetivo de garantir a segurança pública, de regular o trabalho nas indústrias e de melhorar as condições sanitárias das cidades, dentre outros. Esse conjunto de leis transforma-se, assim, em um significativo instrumento urbanístico utilizado pelo Estado, que passou, cada vez mais, a intervir no processo de transformação das cidades, discriminando as exigências públicas e, principalmente, os interesses da emergente burguesia, proprietária do capital e dos meios de produção e como tal uma classe privilegiada.

Com a aplicação nas cidades dos instrumentos legais e das novas realizações técnicas, inaugura-se a era da urbanística moderna. Entre os instrumentos, destaca-se o conjunto de leis que contempla principalmente a expropriação de terras urbanas ${ }^{3}$. Esse instrumento, na visão de Benevolo (2010, p. 82), "[...] permitiu que o administrador público Haussmann, efetuasse seus trabalhos de transformação de Paris, em um clima político autoritário. " O conjunto de intervenções urbanísticas de Haussmann, realizadas na década de 1850, expressou a forte intervenção do Estado na cidade, especificamente, em sua parte central. Incorporava o discurso das preocupações higienistas, da reforma e da demolição de áreas e de edificações degradadas, em condições sanitárias precárias (CALABI, 2012).

Embora o discurso das intervenções de Paris fosse o de modernizar e de embelezar a cidade, ele escondia objetivos políticos e imobiliários. Como político, o interesse era impedir as manifestações da população, que eram frequentes na época. Com relação ao interesse imobiliário, segundo Benevolo, "[...] as obras públicas não fizeram somente subir os preços dos

\footnotetext{
${ }^{3} \mathrm{O}$ poder do Estado de expropriação já era conhecido entre os gregos e os romanos, precursores da cultura jurídica ocidental. O que se alteraram, ao longo da história, foram objetivo, forma de fazê-lo e conteúdo do que se estabelece como sendo justo ou razoável para o ato em si, para pagamento, a título de indenização (RABELLO, 2017).
} 
terrenos circundantes, mas influenciaram em toda a cidade, favorecendo seu crescimento e aumentando as rendas" (2010, p. 102). Além disso, o processo significou a expulsão dos antigos moradores, a maioria operários, da área central de Paris, a partir da demolição das ruas e de construções antigas para a abertura de largas avenidas, altimetria uniforme e a padronização das fachadas das edificações (FIG. 1).

Figura 1. Boulevard Haussmann, em Paris.

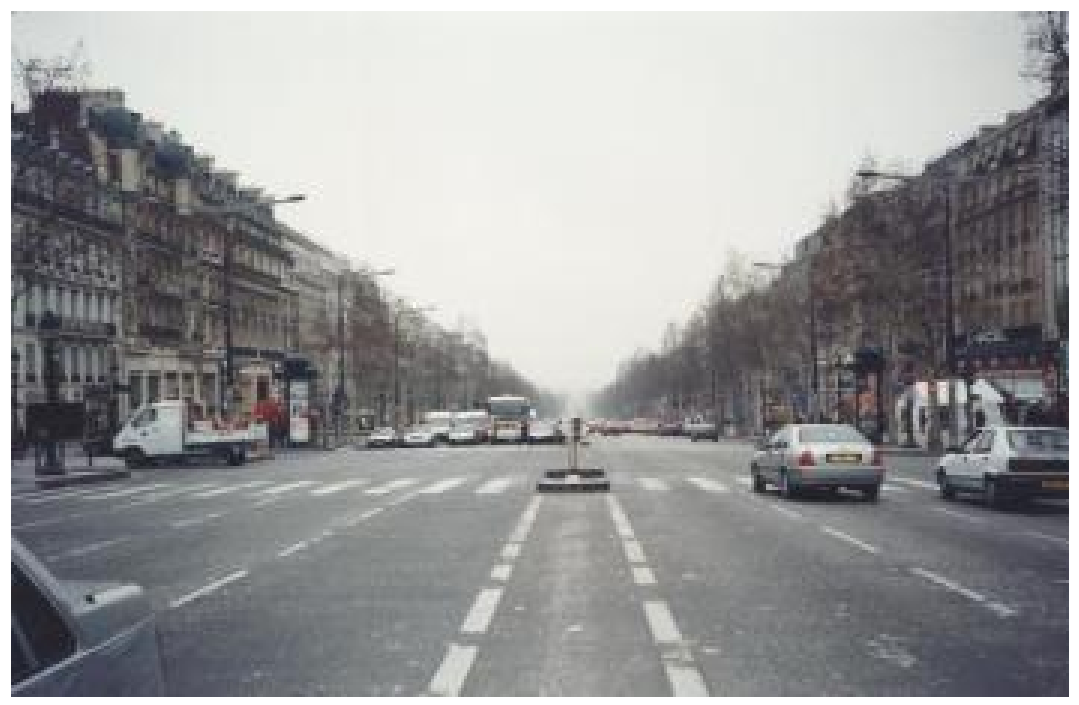

Fonte: do autor, 2014

A grande renovação urbana ocorrida em Paris, na segunda metade do século XIX, representou para Lefebvre (2006) e outros autores como Harvey (2012) a concretização de uma grande estratégia de classe para dominar o espaço. Depois de 1848, a burguesia, como uma classe privilegiada, passa a dominar os meios de produção e os bancos da capital parisiense. Ela se vê, porém, cercada pelos trabalhadores, que se instalam nas periferias imediatas, bem como por antigos operários que chegam a habitar o centro da cidade. Para o autor, o que se pretendia realmente era o aburguesamento do centro da cidade, que tinha como ator principal o Estado interventor e como coadjuvante, a burguesia industrial. A preocupação desta classe privilegiada com as condições sanitárias das cidades foi crucial para o surgimento do Urbanismo Moderno.

Lefebvre revela no "O Direito à Cidade", porém, que esse urbanismo, o Moderno, surge como instrumento comprometido com a proteção do modo de produção e reprodução da sociedade capitalista sob a tutela do Estado. Segundo Martins (2000), "o que não se pode perder de vista é o fato do urbanismo surgir, já em seus prenúncios, inequívoca e umbilicalmente ligado ao Estado moderno e à sua racionalidade". 
As práticas urbanas sobre a tutela do Urbanismo Moderno desempenharam um papel decisivo na absorção de capitais excedentes. Entretanto, segundo Lefebvre, ao preço da destruição criativa da população e da perda de qualquer direito à cidade, já que boa parte da população, excluída das decisões públicas, era remanejada para a periferia ou deslocada para grandes conjuntos habitacionais modernos. Essas práticas sofrerão forte crítica de Lefebvre, que lançará o argumento da reconquista da cidade por aqueles que dela foram excluídos, ou seja, o "direito à cidade", "a vida urbana" (LEFEBVRE 2006, p. 114).

Ao expulsar do centro da cidade os antigos moradores, a burguesia, segundo Lefebvre, expulsa a urbanidade, a vida da cidade, criando espaços vazios (praças, avenidas, etc.) que favorecem o tráfego e o controle policial e militar da população. Com este processo, as massas estão passando por mudanças não só em suas vidas diárias, mas também em sua ideologia. 0 distanciamento do local de trabalho causa perda de vida comunitária e senso de comunidade. Para o autor:

Nessa "desordem", os operários ameaçam os novos ricos, perigo que se torna evidente nas jornadas de junho de 1848 e que a Comuna confirmará. Elabora-se uma estratégia de classe que visa ao remanejamento da cidade, sem relação com sua realidade, com sua vida própria. (LEFEBVRE, 2006, p. 15).

Segundo Lefebvre, uma das últimas etapas deste processo é, desde a década de 1950, o desenvolvimento maciço dos subúrbios sob o controle e o investimento do Estado. Se, durante o período posterior à Segunda Guerra Mundial, confrontado com a escassez de habitação e a urgência, surge a ideia de um "direito à habitação" (que se integra com programas políticos, incluindo programas de esquerda), este direito acaba sendo realizado minimamente (financeiramente e socialmente), justificando a construção de baixa qualidade e de baixo custo. Além disso, para Lefebvre, esse direito obscurece o direito à cidade, isto é, o direito a uma urbanidade real, a uma vida social em uma cidade desenvolvida. O direito à habitação não deve ser negado, mas deve ser o primeiro passo no direito à cidade. Para o autor (2006, p. 18)

Com a criação do subúrbio começa na França um pensamento urbanístico encarniçado contra a Cidade. Singular paradoxo. Durante dezenas de anos, sob a III República, aparecem os textos autorizando e regulamentando o subúrbio habitacional e os loteamentos. Em redor da cidade instala-se uma periferia desurbanizada e, no entanto, dependente da cidade. Com efeito, os suburbanos, os dos pavilhões residenciais ${ }^{4}$, não deixam de ser urbanos mesmo que percam a consciência disso e se acreditem próximos da natureza, do sol e do verde. Urbanização desurbanizante e desubarnizada, pode dizer para ressaltar o paradoxo.

\footnotetext{
${ }^{4}$ Pavilhões são conjuntos residenciais suburbanos formados por edificações unifamiliares. Conjuntos são blocos de apartamentos.
} 
Para realizar esse processo de urbanização, Lefebvre (2006) destaca a ação do Urbanismo Moderno. Ele critica esse urbanismo baseado em uma ciência, às vezes em pesquisas que se destinam a ser sintéticas e multidisciplinares, que acompanha as formas deliberadas de racionalismo operacional, tende a negligenciar o "fator humano". Para o autor:

Este urbanismo se pretende científico. Baseia-se ora numa ciência, ora em pesquisas que se pretendem sintéticas (pluri ou multidisciplinares). Este cientificismo, que acompanha as formas deliberadas do racionalismo operatório, tende a negligenciar o "fator humano", como se diz. [...] Este urbanismo tecnocrático e sistematizado, com seus mitos e sua ideologia não hesitaria em arrasar o que resta da Cidade para dar lugar aos carros, às comunicações, às informações ascendentes e descendentes. Os modelos elaborados só podem entrar para a prática apagando da existência social as próprias ruínas daquilo que foi a Cidade. (LEFEBVRE, 2006, p. 24).

Para ilustrar as graves deficiências das políticas urbanas praticadas nas cidades, segundo Lefebvre (2006), é possível destacar a difícil tarefa da definição da escala adequada da intervenção entre a habitação e o mundo. Com relação a essa habitação os modelos propostos pelo Estado naquela época, segundo o autor, são o pavilhão (com custo elevado, gasto alto de energia, perda de tempo com o transporte por estarem localizados distantes do centro), os grandes conjuntos e o urbanismo técnico (grandes obras como rodovias, aeroportos). Esses modelos perduram até hoje e serão explorados no próximo item deste artigo.

Em "O Direito à Cidade", Lefebvre defende antes de tudo, a vida na cidade para todos e não apenas para as classes privilegiadas. Essa vida para o autor [...] pressupõe encontros, confrontos das diferenças, conhecimentos e reconhecimentos recíprocos (inclusive no confronto ideológico e político) dos modos de viver, dos padrões que coexistem na cidade (LEFEBVRE, 2006, p. 15).

Uns dos grandes méritos de Lefebvre é que, indo além da crítica da situação por ele explorada das práticas do Urbanismo Moderno, em seu livro indica a possível solução, ou seja, a realização da vida na cidade para todos só pode acontecer quando, confrontando a lógica de dominação, prevalece a apropriação do espaço pelos cidadãos. Defende que essa apropriação precisa acontecer coletivamente, como condição à apropriação individual. Segundo o autor, a apropriação que se refere é de uso, "direito à obra e no direito à apropriação (bem distinto do direito à propriedade)" (LEFEBVRE, 2006, p. 135). Exemplifica o caso de uso da cidade com experiência da Comuna de Paris, quando os trabalhadores se reapropriaram do centro da cidade, após terem sido deslocados para a periferia pelo planejamento haussmanniano. 
Esse uso da cidade proporcionaria um novo urbanismo, o da utopia experimental, que parte dos problemas de lugares concretos, onde se desenvolvem relações sociais, e os submete à crítica e à imaginação de novas possibilidades. O papel da ciência é auxiliar e estudar as implicações e consequências das novas formas de apropriação inventadas pelos cidadãos. Esse urbanismo, conforme o pensamento inovador de Lefebvre, tem como protagonista do processo de (re)produção do espaço, a classe trabalhadora, que assim o faria de forma democrática e não como tem sido realizada, tecnocrática e sem participação popular. Harvey (2012) consente com Lefebvre, ao afirmar que como o processo urbano é o principal canal de utilização do excedente, estabelecer uma administração democrática sobre sua organização constitui o direito à cidade.

Entretanto, diante da realidade atual das ações do Estado sobre o espaço urbano, com intervenções que visam atender principalmente o mercado imobiliário, por exemplo, que contam com uma camuflada participação popular, distante da "apropriação" preconizada por Lefebvre, percebe-se que o direito à cidade ainda é algo distante. Um exemplo dessas ações, onde o Estado é o agente promotor, é a construção de grandes conjuntos habitacionais destinados para a população de menor poder aquisitivo.

\section{A (RE)PRODUÇÃO DO ESPAÇO BELORIZONTINO: OS CONJUNTOS HABITACIONAIS DA REGIÃO NORDESTE}

Belo Horizonte foi inaugurada no final do Século XIX. A área urbana, dentro dos limites da atual Avenida do Contorno, recebeu ao longo do tempo mais infraestrutura urbana. Ali, e continua assim até os dias atuais, concentrou-se a maior parte dos principais serviços da cidade, das atividades como comercio e equipamentos públicos. Já a área fora dos limites da Avenida do Contorno cresceu sem planejamento, recebendo infraestrutura somente após parte das ocupações já estarem consolidadas. Os bairros surgiam mesmo sem a infraestrutura e os serviços mínimos. À medida que a cidade se industrializava, ampliava sua área urbana, a desigualdade social aumentava, surgindo inúmeros assentamentos informais nos arredores desses bairros, mas também próximos aos bairros localizados na área central da cidade (ARREGUY, RIBEIRO, 2008).

A industrialização de Belo Horizonte, ocorrida a partir da década de 1940, promoveu um processo de implosão-explosão de sua estrutura urbana (ALMEIDA, 2017). Lefebvre (2006, p. 25) afirma, que "a cidade industrial [...] precede e anuncia a zona crítica. Nesse momento, a 
implosão-explosão produz as suas consequências". A implosão, pelo autor, é interpretada como tendência à aglomeração, verticalização nas áreas centrais, significando uma retomada dessas áreas como espaços privilegiados. Em Belo Horizonte, na medida em que as industriais eram implantadas, a área central, principalmente ao longo da Avenida do Afonso Pena, era ocupada por grandes prédios. Esse processo iria espalhar-se por outras avenidas e ruas da área central, até os dias atuais, com consequências, como a alta densidade construtiva e demográfica, poucas áreas livres, problemas de mobilidade, dentre outros.

Já a explosão, segundo Lefebvre, corresponde a um processo de urbanização estendida, resultando na ocupação de áreas distantes das centralidades principais. Essa implosão da área rural marca o processo de urbanização de Belo Horizonte e ainda ocorre, contando com o apoio do Estado, que vem favorecendo iniciativas privadas de urbanização de terrenos periféricos, contribuído com infraestrutura básica ou flexibilizando legislações ambientais para favorecer ocupações de áreas frágeis ambientalmente. Lefebvre (2006) em "O Direito à Cidade", já alertava para essa união do Estado com a burguesia para patrocinar empreendimentos de interesse do último.

Para facilitar o processo administrativo da cidade frente a essa realidade de implosão, desde a inauguração cerca de $90 \%$ da população da cidade reside fora da Avenida do Contorno, na década de 1980, foram definidas unidades administrativas que ficaram conhecidas como regionais. Atualmente, existem nove regionais na cidade. Dentre as regionais, destaca-se a Nordeste (FIG. 2). 
Figura 2. Regionais de Belo Horizonte

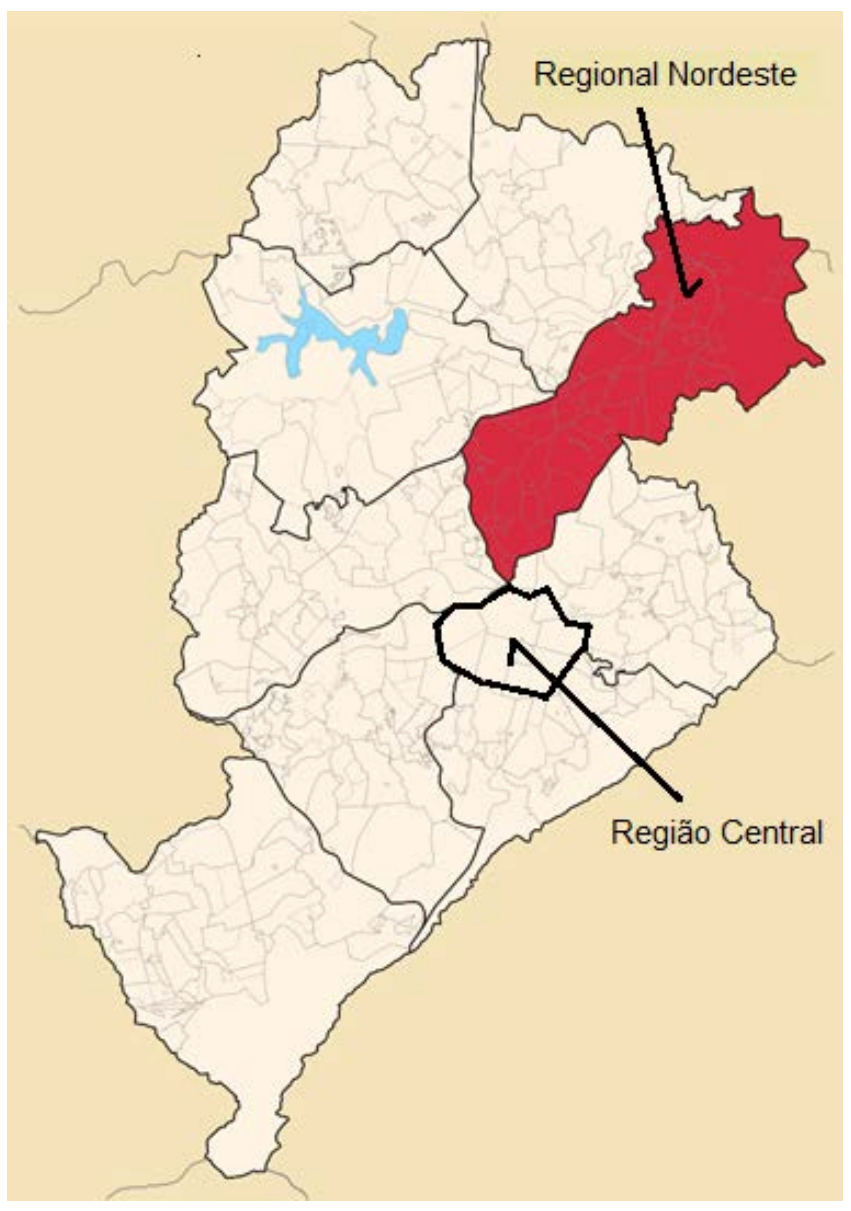

Fonte: Portalclicknegocios, 2018.

Anteriormente, a Regional Noroeste consistia na área rural da nova capital de Minas, sendo ocupada por grandes fazendas. A partir da década de 1920, verifica-se uma grande proliferação de bairros populares. As primeiras construções eram simples, refletindo as condições dos moradores, grande parte funcionários da prefeitura (ARREGUY, RIBEIRO, 2008).

Com o início e a consolidação da industrialização da cidade, ocorre a expansão do tecido urbano, principalmente pela área rural da região nordeste de Belo Horizonte. Lefebvre (2006), no "O Direito à Cidade", revela que a periferia da cidade explode com a extensão de tecido urbano, carregando consigo as condições de produção antes restritas às cidades estendendo-as ao espaço regional imediato. 
Já no final da década de 1930, na região noroeste da cidade, a cerca de 4 Km da região central, foi inaugurada pela iniciativa privada, com o incentivo do Estado que executou o acesso, uma fábrica de tecidos. No seu entorno ergueu-se um "pavilhão residencial" destinado aos operários, que mais tarde deu origem ao bairro Renascença (FIG. 3).

Figura 3. Indústria e bairro Renascença, 1940.

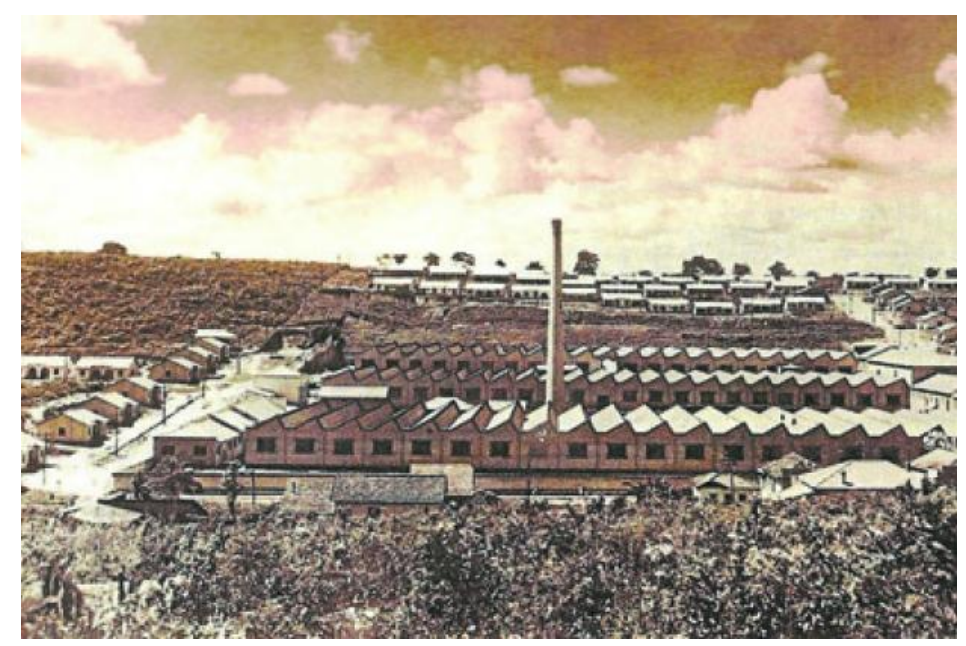

Fonte: Arquivo Público Mineiro, 2017 a.

Ainda nesse período, o perfil popular da região Noroeste foi incrementado com ações do Estado. Este, para abrigar parte da população de menor poder aquisitivo que viviam no centro da cidade, constrói um grande "pavilhão residencial", com cerca de 200 unidades, a cerca de $5 \mathrm{~km}$ da área central da cidade. Esse conjunto habitacional ficou conhecido como Cidade de Ozanan. (FIG. 4). Tanto a vila de operários da Renascença, como a cidade de Ozanan, representavam na época um significativo percentual da população da cidade (ARREGUY, RIBEIRO, 2008). 
Figura 4. Inauguração da Cidade de Ozanan (final da década de 1930).

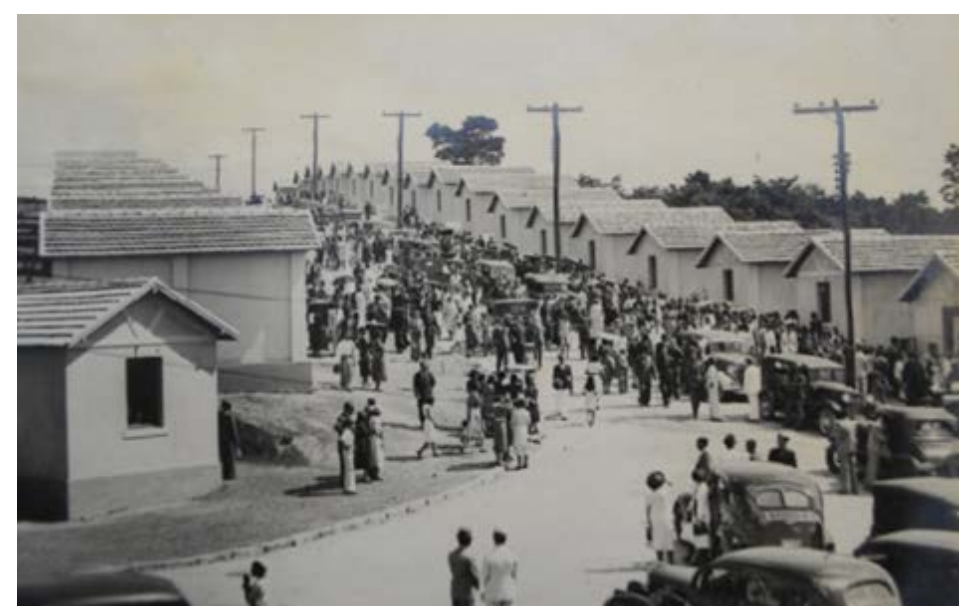

Fonte: Arquivo Público Mineiro, 2017b.

Mais tarde, na década de 1960, quando o Estado dotou a região nordeste de infraestrutura, como agua, luz, melhores acessos, sugiram, no entorno da região central, bairros da iniciativa privada, destinados à classe de maior poder aquisitivo, como é o caso dos bairros Cidade Nova, Silveira e Nova Floresta. A região Nordeste, destinada inicialmente à construção de residências e pequenos prédios, acaba com os novos bairros, atraindo também a classe burguesa, tornando-se uma alternativa à zona central, em processo de explosão (ARREGUY, RIBEIRO, 2008).

Atualmente, a região nordeste ou Regional Nordeste, possui significativas diferenças, tais como a ocupação de bairros de classes média e alta e outros com os menores IDH's da cidade. Sua população total, distribuída em 69 bairros, corresponde a 12\% da população de Belo Horizonte. Sua extensão territorial é de $39 \mathrm{~km} 2$, ou seja, $11 \%$ da extensão territorial da cidade (BELO HORIZONTE, 2018). Pesquisa realizada em 2017, “[...] revela a carência de atividades de comércio e serviço em áreas mais periféricas, situadas na Região Norte e Noroeste" (ALMEIDA, 2017).

Em Belo Horizonte verifica-se um esgotamento de áreas livres para novos empreendimentos imobiliários, principalmente parcelamento do solo. Segundo dados da PBH, em 2000, existiam cerca de 60 mil lotes vazios. Em 2010, esse valor reduziu para 20 mil (ALMEIDA, 2017). 
O reflexo dessa raridade, consequência da pequena extensão territorial junto à urbanização intensiva do solo e extensão do seu tecido urbano patrocinada pelo Estado, repercute também em programas habitacionais como o PMCMV (Programa Minha Casa Minha Vida) que enfrenta fortes problemas para aumentar a participação em BH, em função da escassez de terrenos. Isto, aliado ao alto preço dos terrenos e às condições físicas e ambientais mais restritivas, acaba por provocar uma procura do capital imobiliário por áreas mais distantes do centro e mais acessíveis financeiramente (URBEL, 2014). No período de 2010 a 2017, em Belo Horizonte, somente foram licenciados dois empreendimentos do PMCMV, para a faixa de um a três salários mínimos, os conjuntos Bairro Vitória II e o Parque Real, os dois localizados na antiga Fazenda denominada como Capitão Eduardo, Regional Noroeste divisa com o município de Sabará e distante do centro em cerca de 14 Km (ALMEIDA, 2017).

Em Belo Horizonte, o déficit habitacional para essa faixa é em torno de 50.000 famílias (URBEL, 2014). Observa-se na região central da cidade, "tendência forte de esvaziamento populacional na região do hipercentro de Belo Horizonte. Os dados de redução de população são bastante enfáticos. Junto também com o aumento de prédios comerciais vazios" (PONTES, 2006). Estudos da PBH indicam uma ocupação maior dos primeiros e segundo pavimentos das edificações, como o uso comercial popular e um esvaziamento dos demais pavimentos (BELO HORIZONTE, 2017a). Apesar de estudos afirmarem a possibilidade da utilização desses pavimentos para a habitação popular próximos ao comércio popular, a PBH não tem políticas de incentivo desse uso, pelo contrário, vem realizando grandes projetos de revitalização da área central, o que vem ocasionando a valorização dos imóveis (PONTES, 2006).

Junto ao mercado imobiliário, o Estado vem, através de incentivos de execução de infraestrutura e flexibilização da legislação de uso do solo, favorecendo a ocupação de áreas mais periféricas, como é o caso da antiga Fazenda Capitão Eduardo, na Regional Nordeste, distante dos recursos e atrativos do centro da cidade. Conforme Lefebvre (2006: 15) afirma, "a nova classe dominante, expulsa do centro urbano e da própria cidade o proletariado, destruindo a urbanidade", já que as novas áreas não possuem os equipamentos existentes na área central da cidade. Conforme o histórico do processo de ocupação urbana, a região vem sendo ocupada de forma desordenada e em locais impróprios para habitação, como em áreas de encostas, de declividade acentuada e margens de córregos. Existem vilas compostas por moradias improvisadas e barracos, bem como loteamentos clandestinos regularizados posteriormente pela PBH (BELO HORIZONTE, 2017a). 
Lefebvre, no livro "O Direito à Cidade", já criticava a suburbanização da cidade praticada pelo Estado. O autor afirma que "com a suburbanização principia um processo que descentraliza a Cidade. Afastado da Cidade, o proletariado acabará de perder o sentido da obra (LEFEBVRE, 2006, p. 17).

O Bairro Vitória II constitui um grande conjunto habitacional do PMCMV, direcionado para a população com renda de até três salários mínimos. A escolha, a compra do terreno e as construções do conjunto foram executadas por uma empresa privada (BELO HORIZONTE, 2017b) (FIG. 5).

Figura 5. Conjunto habitacional Bairro Vitória II, em 2015.

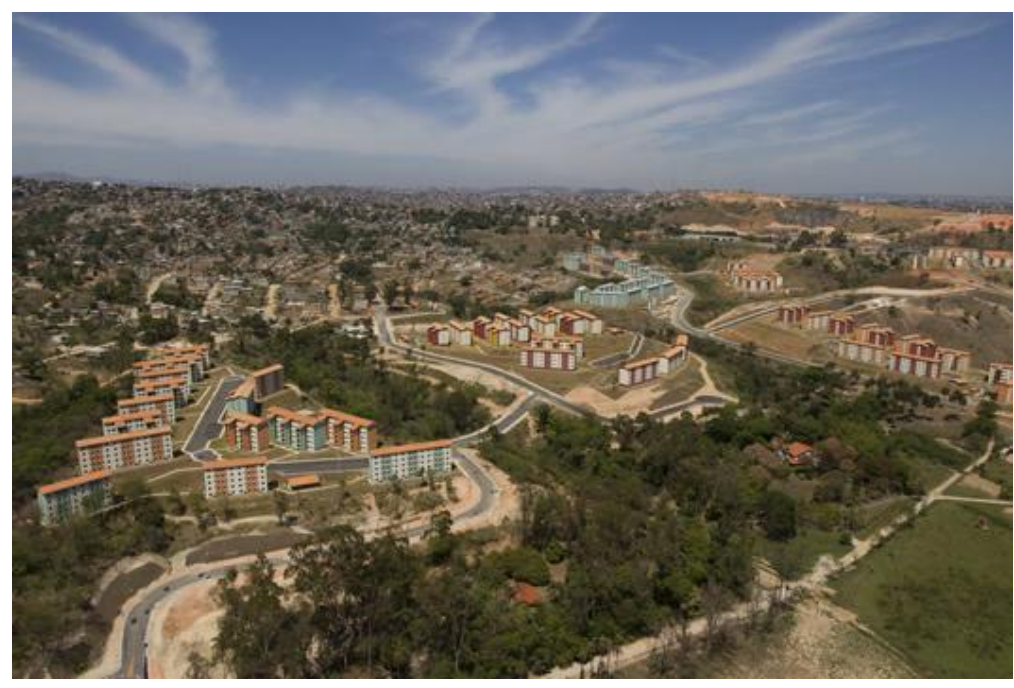

Fonte: Belo Horizonte, 2015.

O terreno possui uma área de aproximadamente $490.000 \mathrm{~m}^{2}$. Ao todo foram construídos seis condomínios, com 1.990 apartamentos residenciais, distribuídos em 59 blocos e 297 lotes residenciais e não residenciais (comércio e serviços), em torno de $360 \mathrm{~m}^{2}$, além dos percentuais públicos de área legalmente exigidos para transferência ao Município (ELUP, sistema de circulação viária e áreas para equipamentos urbanos e comunitários). Parte da infraestrutura urbana ficou por conta da PBH e o custo de sua execução entrou como subsídio para os futuros moradores. Tal iniciativa viabilizou a execução do empreendimento, visto o alto custo da infraestrutura devido as condições físicas do terreno e à distância das redes de água e esgoto. As edificações multifamiliares do Bairro Vitória II possuem cinco pavimentos, com uma variação de quatro a seis unidades por pavimento. Os apartamentos seguem um padrão de dois 
quartos, sala, banho social, cozinha e área de serviço, com uma área total de 47,00 m2 (BELO HORIZONTE, 2017b).

O empreendimento Parque Real está localizado em uma área com aproximadamente 419.000,00 $\mathrm{m}^{2}$, próximo à divisa com o município de Sabará, cujo principal acesso é pela BR 381 e lindeiro ao Bairro Vitória II. O uso residencial unifamiliar é predominante no seu entorno. O empreendimento Parque Real é composto de oito conjuntos residenciais, totalizando 2.470 unidades, lotes residenciais $\left(44.995,03 \mathrm{~m}^{2}\right)$, lotes comerciais $\left(11.175,91 \mathrm{~m}^{2}\right)$ além de áreas a serem transferidas ao município (áreas verdes e de equipamentos com 140.761,02 m²) (BELO HORIZONTE, 2017c) (FIG. 6).

Figura 6. Conjunto habitacional Parque Real, em 2015.

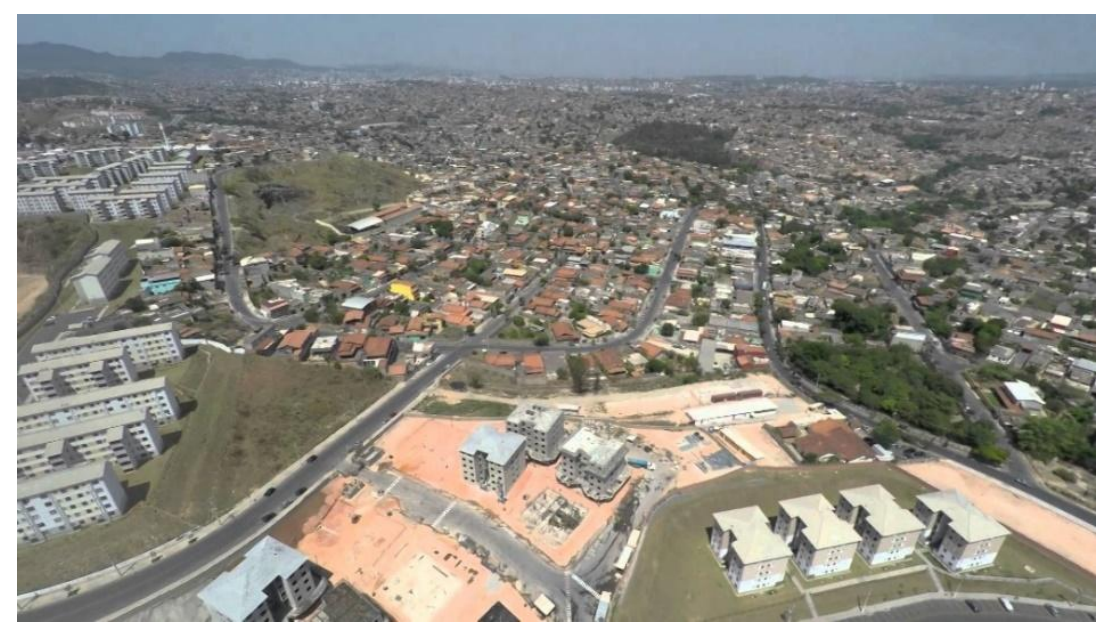

Fonte: Belo Horizonte, 2015.

O programa básico dos dois conjuntos consiste em grandes parcelas destinadas para os condomínios com edificações verticalizadas, lotes individuais ao redor dos acessos principais, destinados ao comércio e aos serviços, áreas institucionais e ELUP, correspondentes aos percentuais exigidos pela legislação municipal. Como a prioridade são as unidades habitacionais, as áreas públicas, como as áreas de equipamento público, acabam por serem aquelas que, pelas declividades, não se prestam para a implantação de casas, ficando localizadas em extremos do projeto e de não situá-las em locais centrais e de fácil alcance do caminhar humano. Até o hoje, somente duas escolas de ensino fundamental foram implantadas, O que é insuficiente para atender toda a demanda (URBEL, 2017).

O impacto urbanístico e ambiental de implantação dos conjuntos é considerado de alta magnitude e de grande relevância, visto que ocorreu a alteração na qualidade ambiental da 
área com perda expressiva da vegetação existente (supressão de $100 \%$ da vegetação existente) (BELO HORIZONTE, 2017b).

O preço da terra e da infraestrutura têm fomentado a reprodução de assentamentos periféricos, como os que foram construídos pelo BNH, na década de 1970, em Belo Horizonte, e agora os do PMCMV, como os do Bairro Vitória I e o Parque Real. Esses conjuntos são entregues prontos, ou seja, não há participação dos futuros moradores na elaboração do programa. Não importa as necessidades dos moradores, todos terão uma unidade padrão de dois quartos. Tanto os conjuntos habitacionais atuais, quanto os antigos, apresentam carência de diversos equipamentos comunitários (BELO HORIZONTE, 2017b) (BELO HORIZONTE, 2017c).

O que Lefebvre declara é que é impossível resolver o problema urbano somente com obras, sem atuar em parâmetros sócio-políticos. E mais do que isso, com relação à prática projetual, afirma que os arquitetos elaboram seus projetos "[...] não a partir das significações percebidas e vividas por aqueles que habitam, mas a partir do fato de habitar, por eles interpretado" (LEFEBVRE, 2006, p. 109).

Verifica-se nos projetos, até agora contratados pelo PMCMV em Belo Horizonte, uma periferização cada vez maior das ofertas. Isso acaba por estimular ainda mais a fragmentação e a hieraquização do tecido urbano da cidade. Como em décadas anteriores, com os famosos bairros populares implantados na área rural da cidade, o Estado continua a incentivar a periferização dessa produção de habitação. Ainda que estes conjuntos possam resultar em um importante benefício para os moradores, a tendência é que a expansão geográfica da urbanização capitalista em Belo Horizonte amplie o padrão de segregação socioespacial, implantando grandes áreas residenciais distantes de equipamentos e serviços, distantes das qualidades que centralidades urbanas proporcionam, situação revelada, criticada por Lefebvre e expostas, desde a década de 1960, no livro "O Direito a Cidade. Depois de tantas décadas, o Estado e a burguesia na cidade contemporânea continuam a patrocinar intervenções na cidade, que apesar do discurso de melhoria de vida, escondem o lado perverso da acumulação do capital, do predomínio do valor de troca sobre o de uso.

Cabe por fim destacar que para Lefebvre o direito à Cidade se confunde muitas vezes com a questão da moradia, reduzida a unidade habitacional. Para o autor "a questão da moradia, sua urgência das condições do crescimento industrial inicialmente ocultaram e ocultam ainda os problemas da cidade" (LEFEBVRE, 2006, p. 76). Muito mais do que isso, seria o "direito à vida urbana, à centralidade renovada, aos locais de encontro e de trocas, aos ritmos 
de vida e empregos do tempo que permitem o uso pleno e inteiro desses momentos e locais" (LEFEBVRE, 2006, p. 143).

\section{CONSIDERAÇÕES FINAIS}

No livro "O Direito à Cidade, Lefebvre tornou-se uma das primeiras vozes no mundo a revelar as relações entre a produção do espaço e o capital. O modo de produção capitalista encontrou na cidade, com a colaboração das práticas urbanísticas, o ambiente adequado para sua expansão. Ele criticou Haussmann, que, com o discurso da modernização de Paris, reestruturou a região central da cidade, entretanto derrubando grande parte da cidade e, depois, construindo de novo, para uma outra classe social: a burguesia. As pequenas ruelas medievais, habitadas de pequenos mercadores, comerciantes, que vendiam serviços, cheia de vida, da gente circulando, foi demolida, para dar lugar aos grandes bulevares, imponentes, largos e embelezados por árvores dispostas harmoniosamente e artificialmente. O que estava facilitando era a circulação, não exatamente das pessoas e da vida, mas, sim, como afirmou Lefebvre, a circulação do capital. Boa parte da população é transferida ou explusa para a periferia, distante do centro, do poder, da festa.

Outra prática do Urbanismo Moderno criticado por Lefebvre foi a dos grandes conjuntos habitacionais que eram construídos na periferia das cidades. Esses conjuntos, segundo o autor, e como se pode verificar até hoje, procuravam atender a uma população que não tinha o direito de indicar suas necessidades. Essas eram e são indicadas pelo Estado ou pelos arquitetos. Tal situação negava uns dos aspectos mais importantes presentes em seu livro manifesto: a apropriação da cidade entendida como participação dos atores que participam de sua produção e não apenas a classe burguesa

Essas práticas sob o impulso do capital, segundo Lefebvre em seu livro, disseminadas pelo mundo e adotadas pelo Urbanismo Moderno, levam a uma evolução qualitativa negativa das cidades, sendo a antiga urbanidade presente nas centralidades urbanas, devastada ou congelada. Ele, diante da crítica a essa situação, das perdas da interação social e da diversidade, do sufoco às manifestações coletivas provocadas pelos padrões impostos pelo Estado, e de forma revolucionária, proclama a luta pelo direito à vida urbana. 
O seu manifesto pelo direito à Cidade foi lançado em um momento, no qual as premissas do Urbanismo Moderno voltadas para o automóvel e a negação da cidade tradicional, dominavam as práticas urbanas das cidades no mundo pós-guerra. Decorridas décadas da publicação, as ideias de Lefebvre sobre as cidades têm se mostrado duradouras. Em sua publicação escreve sobre a segregação socioeconômica e o fenômeno de afastamento da população dos benefícios gerados pela urbanização.

Para elaborar sua tese manifesto, ele refere-se à população forçada a viver em verdadeiros guetos residenciais longe do centro da cidade, como ocorrem nos atuais conjuntos habitacionais do PMCMV, Bairro Vitória II e Parque Real. Anuncia a ausência de participação na formação da cidade por aqueles que foram excluídos do desenvolvimento econômico e aqueles que estão sofrendo com políticas excludentes. Perante este cenário, ele evidencia a necessidade do direito à cidade, como uma recuperação coletiva do espaço urbano por grupos marginalizados, principalmente os que foram deslocados para as áreas periféricas da cidade.

Entretanto, Lefebvre não ficou apenas na crítica das práticas urbanas segregadoras. Além da crítica, apresenta caminhos possíveis para proporcionar a conquista do direito à cidade, daqueles que dela, foram excluídos. Defende a necessidade de avaliar vários métodos de conhecimento para apreender a práxis da cidade. O autor afirma que uma mudança pode ser concretizada na pratica social, a partir de uma realidade que conserve a imagem da cidade enquanto valor de uso. Essa nova forma de ver e apropriar a cidade serão exploradas em obras posteriores do Lefebvre.

Os conjuntos do PMCMV em Belo Horizonte, Bairro Vitoria II e Parque Real, implantados na Regional Noroeste, demonstram como que o Estado continua, como indicado por Lefebvre, apoiando as iniciativas capitalistas de urbanização de áreas distantes do centro. Para viabilizar tais iniciativas é necessário a execução de obras de infraestrutura básica, como água, luz e esgoto. As demais, como equipamentos comunitários, praças, serviços ficam para depois e, como tal, sofrem a concorrência da precariedade desses usos na cidade. Tal produção promove então, em Belo Horizonte, a ocupação de áreas ambientalmente frágeis, com populações de baixo poder aquisitivo, em apartamentos padrões e sem os equipamentos necessários para proporcionar o mínimo de urbanidade.

O mundo mudou muito, desde que o livro de Lefebvre foi publicado. Nas últimas décadas, vem ocorrendo uma acelerada transformação com o desenvolvimento da tecnologia e da informação, dos meios de comunicação, bem como a globalização dos sistemas de produção, transações financeiras e das políticas neoliberais. O ambiente das cidades já não é o mesmo. 
Entretanto, o manifesto revelado por ele da reconquista do direito à vida urbana pelos dominados e excluídos continua atual.

A economia capitalista, cada vez mais globalizada, a biodiversidade e até os recursos naturais são vistos como possibilidade de lucro, sem preocupações em relação à sua preservação ou ao futuro de todos. Ou seja, não é diferente do Século passado. O capital continua sendo a mola propulsora da "não cidade", como definido por Lefebvre. Apesar de existirem inúmeros imóveis vazios no centro de Belo Horizonte que poderiam servir como moradias populares, o Estado, sobre influência de classes privilegiadas, prefere investir em áreas distantes e de difícil urbanização para implantar novas moradias. Mas, ao dotar essas áreas de infraestrutura, abre nova frente para o capital e preserva o centro para empreendimentos lucrativos proporcionados pelos programas de revitalizações.

Passados 50 anos, os argumentos de Lefebvre ainda são atuais e suas ideias ainda são uma utopia, principalmente para as populações de menor poder aquisitivo. O Estado continua com as políticas de incentivar o proletariado a ser deslocado para a periferia das cidades, para áreas distantes do centro. Nesse sentido, para Belo Horizonte o direito à cidade é um ideal distante a ser conquistado.

O espaço de Belo Horizonte, cada vez mais, e conforme já dizia Lefebvre em seu livro, passa a pertencer a determinada estratégia de classe, que precisa do Urbanismo para realizá-lo. Impõe-se a privação da vida urbana com segregações e fragmentações que impedem encontros e oposições.

Lefebvre, mais do que apontar a falência dos projetos urbanos, repudia o caráter alienante da própria pretensão de simplificar os problemas urbanos uma questão meramente administrativa, técnica, científica promovidas por políticas urbanísticas do Estado. Essa situação, para o autor, promove uma total alienação dos cidadãos, tornando-os mais objetos do que sujeitos do espaço social. O Estado autoritário planificador pode até eventualmente resolver parte das necessidades materiais, como moradia e transporte, mas ao custo de privar as pessoas da condição de sujeitos da construção da sua própria cidade.

Lefebvre apresenta um urbanismo determinado por estratégias do Estado, onde a cidade se torna um instrumento político e de controle. Observa-se que as estratégias de dominação privilegiam determinadas áreas urbanas de acordo com seus interesses e a população envolvida fica à mercê das decisões.

No caso da habitação, falar em direito à cidade aponta para uma dimensão coletiva maior que não está inscrita apenas a aquisição da casa. Não ter casa não significa apenas não 
poder permanecer fisicamente na cidade, mas não pertencer a seus laços sociais. Conseguir emprego ou usufruir da maioria dos serviços públicos tornam-se tarefas praticamente impossíveis sem endereço fixo, por exemplo. Com a negação do direito à moradia e do acesso à habitação, o pertencimento à cidade também é negado - e essa dimensão não é só individual, na medida em que determina quem pode fazer parte da cidade.

A lógica da produção do espaço nas cidades contemporâneas como em Belo Horizonte continua a mesma que foi apontada e criticada por Lefebvre em seu livro. O espaço continua sendo produzido segundo o interesse da reprodução do capital. O Estado ainda continua participando da produção de um espaço valorizado diferencialmente, segundo interesses da classe dominante, enquanto que as pessoas que vivenciam realmente, circulam, trabalham e criam ligações com o espaço, ficam à mercê dessa produção.

Ainda distante e passadas tantas décadas do lançamento do manifesto de Lefebvre do direito à Cidade, de um mundo transformado e renovado, parece ser o seu manifesto, uma utopia inalcançável, e por isso deveria ser abandonada. Mas como nos ensinou, existem possibilidades, como os dos levantes de grupos oprimidos. E, além disso, como disse Lefebvre, quem não é utopista?

\section{REFERÊNCIAS}

ALMEIDA, Reginaldo Magalhães de. Contradições da produção de espaço de Belo Horizonte: a raridade de novos parcelamentos do solo. Revista Digital Ocullum Ensaios. N N 14/3. PUCCampinas. Disponível em: http://pt.calameo.com/read/002812705695fe493764e. Acessado em: 13 de dezembro de 2017.

ARQUIVO PÚBLICO MINEIRO. Foto da Vila Ozanam. Coleção Fotos de Belo Horizonte do Arquivo Público Mineiro. Meio digital. Disponível em: http://www.siaapm.cultura.mg.gov.br/modules/grandes_formatos_docs/photo.php?lid=453. Acesso em: 21 ag. 2017b.

ARQUIVO PÚBLICO MINEIRO. Foto da Vila Renascença. Coleção Fotos de Belo Horizonte do Arquivo Público Mineiro. Meio digital. Disponível em: http://www.siaapm.cultura.mg.gov.br/modules/grandes_formatos_docs/photo.php?lid=453. Acesso em: 21 ag. 2017a. 
ARREGUY, Cintia Aparecida Chagas; RIBEIRO, Raphael Rajao. Histórias de bairros [de] Belo Horizonte: Regional Nordeste. Belo Horizonte: APCBH; ACAP-BH, 2008.

BAUMGARTEN, M. Sociedade e conhecimento: ordem, caos e complexidade. Sociologias, v. 8, n. 15, p. 16-23, 2012.

BELO HORIZONTE. Prefeitura Municipal. Prefeitura Municipal. Estatística e informações históricas sobre Belo Horizonte. Disponível em: http://portalpbh.pbh.gov.br/pbh/ecp/busca.do;jsessionid=A15BOFBFC32C147399CB98699D19F 116.portalpbh1b?busca=informa\%C3\%A7\%C3\%B5es+hist\%C3\%B3ricas\&evento=Ok. Acessado em: 27 de setembro de 2017a

BELO HORIZONTE. Prefeitura Municipal. Processo administrativo $\mathrm{n}^{\circ}$ 01.053.016.10.41 do Conjunto Bairro Vitória II. Belo Horizonte, Secretaria Municipal de Meio Ambiente, 2017b.

BELO HORIZONTE. Prefeitura Municipal. Processo administrativo $\mathrm{n}^{\circ}$ 01.053.016.10.54 do Conjunto Paulo VI. Belo Horizonte, Secretaria Municipal de Meio Ambiente, 2017c.

BELO HORIZONTE. Prefeitura Municipal. Processo administrativo $\mathrm{n}^{\circ}$ 01.089.017.14.01 da Fazenda Capitão Eduardo. Belo Horizonte, Secretaria Municipal de Meio Ambiente, 2017d.

BENEVOLO, Leonardo. História da Arquitetura Moderna. São Paulo: Editora Perspectiva, 2010.

CALABI, D. História do urbanismo europeu: questões, instrumentos, casos exemplares. Perspectiva, São Paulo, 2015.

CONCEIÇÃO, MARCUS VINICIUS COSTA DA. Henri Lefebvre e a Internacional Situacionista: o debate sobre a Comuna de Paris no contexto do Maio de 1968 - Anais do XXVI Simpósio Nacional de História - ANPUH - São Paulo, julho 2011.

DEULCEUX, Sandrine; HESS, Remi. Henri Lefébvre - vie - oeuvres - concepts. Paris: Ellipses, 2009. 
HARVEY, David. O direito à cidade Lutas Sociais, São Paulo, n.29, p.73-89, jul./dez. 2012.

LEFEBVRE, Henri. O Direito à Cidade. São Paulo: Ed. Moraes, 2006.

MACHADO, Carlos Roberto. Momentos da obra de Henri Lefebvre: uma apresentação. Revista eletrônica Ambiente \& Educação, ISSN 1413-8638, E-ISSN 2238-5533, Rio Grande do Sul, 2008. Disponível em: <http://www.seer.furg.br/ ambeduc/article/view/977>. Acessado em: 08 de abril de 2013.

MARTINS, José de Souza. Henri Lefebvre e o retorno à dialética. São Paulo: Editora Hucitec, 1996.

MERRIFIELD, Andy. Henri Lefebvre: a critical introduction. New York: Routledge, 2006.

MONTANER, Josep Maria. Sistemas arquitetônicos contemporâneos. Barcelona: Editorial Gustavo Gili, 2012.

MONTE-MÓR, Roberto Luis de Melo. As teorias urbanas e o planejamento urbano no Brasil. In: DINIZ; CROCCO (Ed..). Economia Regional e Urbana: contribuições teóricas recentes. p. 61-85. Belo Horizonte: Editora UFMG, 2006.

PBH. Prefeitura de Belo Horizonte. Dados gerais. Disponível em: http://portalpbh.pbh.gov.br/pbh/ecp/comunidade.do?evento=portlet\&app=regionalnordeste\& pg $=5481 \& \operatorname{tax}=16420$. Acessado: 12 dezembro de 2018.

PONTES, Mateus Moreira. Requalificação do Hipercentro de Belo Horizonte: Possibilidades de inserção do uso residencial. Dissertação apresentada ao Núcleo de Pós-Graduação em Arquitetura e Urbanismo da UFMG, como requisito parcial à obtenção do título de Mestre em Arquitetura e Urbanismo. Área de Concentração: Arquitetura e Urbanismo. Orientadora: Dra. Maria Lúcia Malard. Belo Horizonte, UFMG, 2006. 
PORTALCLICKNEGOCIOS. Figura das Regionais de Belo Horizonte. Disponível em: http://portalclicknegocios.blog.br/category/9-regionais-de-bh/. Acessado 27 em setembro de 2017.

RABELLO, Sonia. A Sociedade em Busca de seus direitos, 2002. Disponível em: <http://www.soniarabello.com.br/biblioteca/Justa_indenizacao_nas_expropriacoes_imobiliarias _urbanas_-_Justica_social_e_o_enriquecimento_sem_causa.pdf>. Acesso em: 4 de abril de 2017.

URBEL. Companhia Urbanizadora de Belo Horizonte. Prefeitura de Belo Horizonte. Relatório anual sobre os aglomerados de Belo Horizonte. Belo Horizonte, 2017.

Trabalho enviado em 24 de fevereiro de 2018

Aceito em 25 de abril de 2018 